\title{
Otra vez Fuensanta: Despedida y Reencuentro
}

El título de la presente conferencia* hará sin duda sonreír a muchos oyentes, quienes un poco incrédulos se preguntarán, no sin fundamento, cómo es posible decir algo nuevo sobre un tópico tan conocido como es el de Fuensanta y López Velarde. Sin embargo, dada la complejidad singular de la obra del poeta zacatecano, creo yo que es casi obligatorio que uno se acerque a ella una y otra vez, con el resultado inevitable de que así se descubrirán nuevos $\mathrm{e}$ insospechados matices de sentido que antes pasaron inadvertidos. En su auténtica dimensión espiritual, la obra de López Velarde no se agota fácilmente, y el escritor no nos revela llana y sencillamente las intensas emociones que dan origen a sus mejores poemas y prosas. En sus raíces de hombre y de poeta, vive una enigmática situación espiritual de que tiene conciencia lúcida. De ahi, pues, las frecuentes zonas de penumbra que caracterizan su expresión lírica, y pienso que con la perspectiva de algunos años y repetidas visitas a su obra habrá algo más que decir sobre las relaciones que lo unían con Fuensanta o que lo separaban de ella.

Mucho se ha escrito sobre el tema amoroso en López Velarde, to. mando en cuenta sus varias y distintas dimensiones. Como es sabido, el amor es tema central en su prosa y en su verso. Para precisar el alcance de esta obsesión femenina del poeta, ya aparente desde los comienzos de su vida literaria, tan sólo hay que recordar, entre otros textos, una breve página escrita un poco antes de su muerte en 1921. Sus palabras son explícitas:

Yo sé que aquí han de sonréír cuantos me han censurado no tener otro tema que el femenino. Pero es que nada puedo entender ni sen.

* Esta conferencia se leyó en el ex templo de San Agustín, Zacatecas, el 11 de junio de 1971, con motivo del homenaje nacional dedicado al poeta Ramón López Velarde en el cincuentenario de su muerte. 
tir sino a través de la mujer. Por ella, acatando la rima de Gustavo Adolfo, he creído en Dios; sólo por ella he conocido el puñal de hielo del ateísmo. De aquí que a las mismas cuestiones abstractas me llegue con temperamento erótico.

Con estas salvedades y con la esperanza de no caer en los lugares comunes de siempre, quisiera volver a hablar de Fuensanta, o, mejor dicho, no de ella exactamente sino de su imagen poética, la que a mi juicio pasa por varias etapas aunque sean tal vez en el fondo idénticas.

Sin remontarnos a la prehistoria, cabe preguntarse iqué representa Fuensanta en la vida y en la obra de López Velarde en sus primeras manifestaciones literarias, entre los años de aproximadamente $1909 \mathrm{y}$ 1912? Antes de intentar una respuesta a esta pregunta introductoria, es necesario recordar aquí que en dos cartas fechadas en el otoño de 1909, dirigidas a su amigo Eduardo J. Correa, habla el poeta del fracaso de su único ensueño de amor y de la ruina de su ilusión. Rota la clave de su vida, como él mismo dice, Fuensanta es un cadáver en su ánima. ¿Cómo explicar la evidente ruptura definitiva a que se refiere López Ve. larde? Creo que es imposible saber con exactitud los motivos que ocasionaton aquella circunstancia tan profundamente sentida por el poeta: Cabe preguntarse, sin embargo, si ya, desde un principio, no se encuentre vacilante entre la profanación del objeto amado y el deseo de mantener la ilusión amorosa. Ciertos textos tienden a sostener esa hipótesis.

De mayor importancia desde el punto de vista literario que aquellas cartas aludidas es una de las primeras prosas de López Velarde, que se publicó con título de "Jugando baraja" en $L_{a}$ Gaceta de Guadalajara en julio de 1909. En esa remota prosa, escasamente conocida y de ela. borado juego simbólico (los naipes son portadores de hondas cosas espirituales y como ellos la vida del poe'a está en las manos de la amada), se alude a la imposibilidad del amor que es solamente una vana ilusión incapaz de ser traducida en la realidad. Se imponen con toda claridad las notas de futilidad y el poeta ya está convencido de que su ensueño de amor no se realizará jamás en la tierra. Sabe que ama a la novia de pro. vincia con afecto insuperable, como dice, pero nunca le hablará de su pasión, siendo eterna la clausura de su boca. En el atardecer piensa en el fracaso y en la fatalidad de los hechos mientras juegan a la baraja $y$, de repente, en un momento vertiginoso pero fugaz las rodillas de ạmbos se tocan por debajo de la mẹsa, Exclama el poeta; 
$\ldots, ;$ Oh segundo memorable y fugaz de aquella noche de octubre! tú supiste de mi religiosa emoción al contacto de la beata humanidad de mi amada con la mía pecadora! Pensé, con tristeza de cataclismo, cómo mientras el alma de ella y la mía bogaban distanciadas en zonas del infinito, las todillas, las terrenas partes, se yuxtaponían por suceso fortuito, acarreando conmociones tan elevadas que sentí vibrar en todo mi ser una suprema voz en apología de la carne.

Después de aquel furtivo contacto físico, avanzada la noche, la prosa se cierra con una nueva insistencia en la futilidad de la plena realización amorosa, y el amante se despide de la mujer. El fragmento copiado de "Jugando baraja" me interesa de modo especial porque en él se refleja ya una importante confusión o perplejidad entre las llamadas de la carne y las del espíritu. Se ve aquí, acaso por primera vez, el endiosamiento de la amada pura y casta, cuyas virtudes se oponen a la entraña pecami. nosa del poeta, a la que tantas veces se alude en la poesía de $L a$ sangre devota. Amar a Fuensanta como mujer sería traicionar el ideal. Es mujer, sí, y el contacto físico conmueve al amante primero por una intensa emo. ción de tipo religioso, luego en sus fibras de hombre apasionado, en cuyo ser palpita una apología de la carne. Pero también la amada es alma y espíritu. Por lo visto, sus almas, paradójicamente alejadas, vuelan en zonas del infinito. ¿Será posible, pues, su unión perfecta solamente más allá de la vida mortal de ambos? López Velarde no ofrece solución al dilema planteado aquí.

Si el lector se toma la molestia de repasar las más tempranas poesías conocidas de López Velarde, obras aforiunadamente desechadas en su mayoría al recoger las definitivas de $L a$ sangre devota y compuestas más o menos entre los años de 1910 y 1912, el sentimiento que se destaca con reiterada insistencia es uno de constante y dolorida despedida a Fuen. santa. La pena es netamente romántica: el joven poeta habla de la fuga otoñal de sus ilusiones quiméricas, de la muerte de su pasión fúnebre, de un amor que se deshoja, y de tópicos semejantes de indiscutible filiación literaria, e incurre así en una retórica sentimental al expresar sus juveniles cuitas amorosas. No obstante su poco valor estético, aquellas primeras poesías de aprendiz —otro tanto podría decirse de sus prosas de aquella época lejana- son de gran interés por temas e imágenes que con el tiempo se refundirán en una poesía más lograda. Impera la misma exaltación de su primera pasión ideal; se entrega el poeta a ingenuas y candorosas hipérboles en la representación de la amada; y no faltan las 
consabidas notas religiosas utilizadas para evocar aquella mujer pura, cuasi mística y siempre casta. A pesar de estas limitaciones estéticas, ya mencionadas de esos poemas, quisiera señalar dentro del contexto del presente trabajo unos cuantos versos. Primero algunos de "Tu voz profética", en los cuales el joven parece darse cuenta del enigma amoroso que está viviendo:

\section{$Y$ nuestro dulce noviazgo será, Fuensanta, una flor con un pétalo de enigma y otro pétalo de amor. ¡Tú me dirás del enigma, yo te diré del amor!}

En otro poema, "El adiós", compuesto en 1912, la despedida parece ser ya definitiva, muertas todas las quimeras e ilusiones de antes. Quisiera señalar que el ambiente, después de evocar a la imagen femenina inaccesible, es fúnebre: se oye el toque de difuntos y se imponen notas sepulcrales. El amor puro, dotado de alas, que el poeta sentía por ella es ahora ya cadáver que en una urna va a presidir el luto del hogar de Fuensanta. Se separan los amantes; ella, por un breve instante, parece conservar su función de purificadora, pero, de repente, la luz que lleva en sus manos frágiles para guiar al pecador se apaga. E irónicamente del trasmundo llega un golpe de aire: un "suspiro de alma en pena / o soplo del Espíritu del mal". Queda en pie una mera imagen de Fuensanta, hecha ya imposibilidad para el poeta condenado a no realizar su anhelo amoroso.

En este contexto es instructivo referirse aquí a una prosa poco conocida de 1914 titulada "Dolor de inquietud", por estar intimamente articulada con el poema aunque el final sea distinto. Al interrumpirse el monólogo del amante, "la amada va delante, como guía providencial que llévase, entre las manos frágiles, una luz", sin que en esta ocasión ésta se extingue. Cabe preguntarse si en la prosa se insinúa la salvación y no la condena total que hemos visto en el poema aludido. En "Dolor de inquietud", la más temprana expresión, entre lírica y alegórica, de la incesante dualidad de su alma, López Velarde es indigno de la mujer sana por estar contagiado de "la pecaminosa inquietud" de su tiempo. Otra vez opone la sensualidad pagana al éxtasis religioso ("si una gota de cera nos da el éxtasis, la otra nos quema con lumbre sensual"). Con clara lucidez se da cuenta de su desorientación espiritual ante estos dos extremos, porque 
"las funciones de la bestia se confunden con los más altos ejercicios espirituales", siendo imposible conciliarlos. La falta de conciliación, palabra clave, lleva a un proceso de autodestrucción y, víctima de "amarguras metafísicas" y de "tristezas trascendentales", de las cuales está exenta la mujer, el amante no puede libertarse del puño férreo del demonio. Pero aún así, como afirma en otra parte, la pugna entre las fuerzas contradictorias le asegura al menos una cierta grandeza moral. $Y$ una última fórmula personal tomada de la misma obra: "Somos a un tiempo sacerdotes sacrílegos del misticismo y paganos traidores a sus amables diosas."

En aquellas primeras poesías, pues, Fuensanta en la lejanía queda en pie entre las catástrofes interiores del poeta y de una manera $u$ otra se relaciona con un pasado. Esta es, desde luego, la misma imagen poética que se da en varias poesías de La sangre devota, en que a su vez se puntualiza la eterna despedida de la amada, ausente en el espacio y en el tiempo. Quisiera añadir aquí que semejantes motivos caracterizan otras prosas suyas escritas en la época inicial, las cuales se relacionan de manera estrecha con su poesía. "La vendedora de pájaros", por ejemplo, recuerda a la grave provinciana que vende "el ave retórica de la ilusión", y en varias ocasiones López Velarde insiste en el contraste que existe entre realidad e ilusión. Fuensanta en el recuerdo constante del poeta va cobrando un nuevo valor espiritual: es el pasado y la juventud, la inocencia perdida y el terruño. Es la alianza eterna pero inaccesible. Por último, López Velarde nos da una posible pero velada explicación de esta ruptura:

No quisimos pasar del prólogo del idilio, e hicimos bien. Jugamos puerilmente en un simulacro sentimental, y nos entretuvimos echando a volar embozadas confesiones de amor, que se deshacían en el aire con el desvanecimiento luminoso de los cohetes multicolores. Nos quedamos en el prólogo y fuimos y seremos felices, porque aspiramos el olor de la manzana del Mar Muerto sin morder su ceniza. Nos divertimos en una comedia emocional -quizá en algo más que una simple comedia-, sin que rozase las alas de nuestro afecto el soplo glacial del tedio, médula gris de todos nuestros goces.

Como tecordé antes, una misma imagen, candorosa e idílica, de Fuensanta continúa en varios poemas de La sangre devota. En otros de su primer libro, los que ahora nos interesan, parece acentuarse, junto con 
las siempre presentes notas de ausencia y despedida, ahora más definitiva por la enfermedad de la amada lejana, una nueva visión de ella más espiritualizada o más profunda, así como una nueva conciencia de la im. posibilidad de recobrarla y de recobrar todo lo que ella significó en su remota juventud provinciana.

En este momento convendría decir algo del libro mismo, cuya ambigüedad se insinúa desde el título. A la sencillez ingenua de antaño y a los poemas inspirados directamente en Fuensanta, se agrega ahora la expresión lírica de otras incitaciones más sensuales, fruto de las nuevas experiencias eróticas del poeta. En la trayectoria sentimental de $L a$ sangre devota la tónica de las poesías de fecha más temprana es el amor ideal y puro; en las otras, de composición más reciente, son claramente visibles las tentaciones carnales que reaparecerán más tarde y con mayor tensión dramática en Zozobra. El poeta puede regresar a la Patrona de su pueblo sí, pero herido en el cuerpo y en el alma; en ese viaje de retorno parte "desde las tenebrosas anarquías / del pensamiento y la conducta". No es, pues, un libro sencillo sino que en él se esbozan ya los conflictos aními$\cos \tan$ característicos por un lado del hombre enamorado de la mujer y por el otro del hombre enamorado de un recuerdo espectral.

En muchas poesías de su primer libro Fuensanta es una presencia concreta y bien definida, que suele ser situada en un ambiente igualmente exacto. No es una abstracción, una mera sombra sino mujer per. cibida sensorialmente. Las virtudes abstractas -el recato, la ingenua sabiduría, la honestidad- las evoca sobre todo en las otras mujeres provincianas menos personalizadas que figuran en otros poemas del libro. Sin embargo, me interesa destacar ahora otro tipo de representación de la amada que motiva la poesía "Pobrecilla sonámbula", cuya fecha de publicación no he podido precisar. Perdiendo peso y contorno preciso, la figura de Fuensanta se desdibuja aquí sensiblemente y trasciende un espacio identificable. Se imponen en aquella evocación de la mujer, siempre frágil, claras notas de ingravidez y transparencia, las cuales tienden a restarle corporeidad en su paso sonámbulo por el mundo y por la conciencia del poeta. Continúa rehaciendo, en su función bienhechora, a los hombres y a las cosas sí, pero se ha convertido ya en una espiritualizada visión del alma y para no dejar lugar a dudas la evoca el poeta en los siguientes términos insistentes:

y es tu sufrido rostro como un éxtasis que dilata en una transparencia. 


\section{Así cruzas el mundo con ingrávidos pies, y en transparencia. de éxtasis se adelgaza ta perfil,}

Por lo demás, no son infrecuentes otras palabras que dan a Fuensanta una parecida cualidad intangible, aunque siempre indemne en el recuerdo del escritor: es fantasma, sombra, ilusión y quimera. No faltan ciertos verbos que dan la pauta para comprender el sentimiento amoroso de López Velarde: venerar, reverenciar, canonizar. Y sabemos, por lo que nos dice el poeta, que su esencia es arcana, su persona etérea.

Los poemas de La sangre devola no se agrupan cronológicamente pero su ordenación me parece bien clara en lo que respecta sobre todo al primer poema, la of renda romántica de sus versos, y al último de amarga despedida. Sobre la poesía final quisiera llamar la atención ahora. En "Y pensar que pudimos. .", cuya versión primera se publicó en 1912 con título de "Rumbo al olvido" y luego de nuevo con el título definitivo en enero de 1916, lo que no ha sido observado hasta ahora, creo, es que el poeta se imagina, en el momento de la muerte o más allá de ella, la posible unión amorosa. Escribe:

\section{...y en una suave}

conjunción de existencias, ver las cintilaciones del zodíaco

sobre la sombra de nuestras conciencias...

y de análoga importancia es una imagen anterior de la danza eierna, quizá fuera de este mundo, en una visión cósmica que anticipa, a no dudarlo, otras de sus últimos poemas:

$$
\begin{aligned}
& \text { Y pensar que pudimos, } \\
& \text { en una onda secreta } \\
& \text { de embriaguez, deslizarnos, } \\
& \text { valsando un vals sin fin, por el planeta... }
\end{aligned}
$$

En múltiples ocasiones López Velarde alude directamente a la enfer. medad cardiaca de que sufría Fuensanta, y en una poesía, "Me estás vedada tú. .." hasta llega a imaginarse su muerte inevitable y casi presentida. Al comentar el poema en cuestión, Octavio Paz se pregunta: "¿Esta vi. sión es de pena o de venganza?" Y continúa: "Quizás de ambas. Es un sactrificio en el çal uno dẹ los dos oficiantes, y no precisamente la vícti- 
ma, es un fantasma. ...Algo más que el temor de perder lo que ama lo lleva a imaginar este final atroz. Se trata de una muerte invocada, deseada..." Aunque creo que la visión es más de pena que de venganza, lo que sí queda en claro es que en la soledad de la agonizante no la acompañará el poeta en su congoja final. En las estrofas iniciales de la composición se lamenta, con un tono ya definitivo, de la imposibilidad de su amor. López Velarde tiene conciencia de no haber podido encontrar en Fuensanta la fórmula escondida de su existencia, y hasta no puede tomarla en brazos:

...como quien levanta

a su propia ilusión incorruptible

hecha fantasma que renuncia al viaje.

Años atrás yo había relacionado esta visión terrorífica de la muerte de la amada con la prosa "Hacia la luz... (Para una enferma)", que data de 1913. Lo vuelve a hacer Paz, pero habría que destacar, a mi juicio, el siguiente fragmento en que el poeta piensa en su propio viaje más allá del mundo, un viaje que al parecer le permitirá reunirse espiritualmente con Fuensanta:

Sí, estás enferma... pero jacaso he creído al soñar con tu garganta de nieve, que será eterna? Yo adoro tu cuerpo por ser la envoltura gentil de tu alma. Si mañana tu alma se liberta, mi amor perdurará sobre el pecho y las manos y los ojos adorados que se pudran en la tiniebla húmeda del ataúd, y aguardaré la hora de mi liberación para ir contigo. $Y$ nuestras almas, mecidas por un soplo de otros mundos, se columpiarán libando la esencia de la misma flor inmortal como dos mariposas diáfanas...

y, como escribe López Velarde, "morir es ir hacia la luz" y en ella se despertarán los amantes, antes tragados juntos por la gigantesca ola negra del mar.

Ya advertí que la fórmula anhelada de su vida se esconde y no se revela por el momento en Fuensanta. No la encuentra o mejor sería decir que no la oye en los latidos del corazón enfermo de la mujer. Con inusitada frecuencia López Velarde afirma que no sabe aclarar las razones de su dolor y de su pesar. Las dudas lo acosan y le impiden que vea con claridad en su situación ambigua. No of rece explicaciones porque no las tiene, ni esa es la función del poeta. Tal estado de ánimo llega 
a su máximo punto de tensión en la poesía "¿Qué será lo que espero?" (1915) de la cual copiamos unos versos explícitos:

si mi voto es que vivas dentro de una

virginidad perenne y aromática, vuélvese un hondo enigma

lo que de ti persigue mi esperanza.

¿Qué le queda al poeta? Solamente unas vagas sensaciones espirituales de paz y de claridad que le vienen de un pasado remoto. Así es que López Velarde, dando vueltas y más vueltas alrededor de su amor enigmático, se propone constantemente preguntas sin posible respuesta, pero que le permiten indagar siempre en la nada clara esencia de su sentimiento amoroso. Al proponétselas se da cuenta de una confusión o de una indecisión que lo hace vacilar entre móviles contradictorios. $Y$ en este contexto hay un poema de La sangre devota, uno de sus momentos más felices, que merece ahora breve atención. Se trata de "En las tinieblas húmedas", composición publicada en 1915 y en la que se resume de modo admirable algunos motivos principales que hemos ido trazando en el presente estudio. En estos versos nocturnos, escritos desde la sole. dad capitalina, el poeta desea explicarse las contradicciones de su amor enigmático.

En la primera estrofa de "En las tinieblas húmedas" López Velarde, como dije, intenta definir el sentimiento ambiguo que le inspira la mujer, pero por su naturaleza está obligado a hacerlo en términos opuestos y contradictorios. Simultáneamente ella le da una pena y un goce. Luego procura precisar más:

algo como la helada virtud de un seno blando, algo en que se confunden el cordial refrigerio y el glacial desamparo de un lecho de doncella.

Tiene plena conciencia de aquella aparente confusión (el verbo confundirse es significativo) y de la imposibilidad de expresar con claridad su emoción contradictoria (dos veces se repite el indefinido algo). Octavio Paz, al ocuparse de esos versos, opina que "la oposición entre 'cordial' y 'glacial' impide la consumación de ese amor y, al mismo tiempo, su confusión lo conserva vivo a lo largo de los años.. La ambigüiedad no reside sólo en el objeto de su adoración sino en sus sentimientos: amar a Fuensanta como mujer es traicionar la devoción que le profesa; venerarla como espiritu es olvidar que también, $y$ sobre todo, es un 
cuerpo." Sin embargo, ahota con mayor seguridad, afirma el poeta que ella es un lampo ante las fauces lóbregas de su apetito y la recuerda en una serie de novedosas imágenes destinadas a recalcar de nuevo su castidad e inocencia. Imagina a Fuensanta en vela nocturna y, recogido en las sombras solitarias de la noche capitalina, sabe que ella -y sólo ellapodrá descifrar y entender la rima recóndita de aquellos versos enigmáticos. Al retomar finalmente otros motivos contradictorios (escarcha, meteoro), los cuales parecen traer eco de la estrofa inicial, su sentimiento angustiado se proyecta a otra dimensión que trasciende los límites físicos del tiempo y del espacio para lograr una permanencia eterna. Hermoso poema que revela cómo hasta en la capital perdura el recuerdo de aquella mujer lejana que resumía para López Velarde toda su ilusionada juventud provinciana.

De modo sorprendente ha cambiado el estilo y el tono de la obra de López Velarde, tanto en el verso como en la prosa, durante la breve época que abarca poco más o menos los tres años que separan la publicación de La sangre devota y Zozobra. Ahora, radicado definitivamente en la capital, es natural que viva nuevas incitaciones más complejas y más inquietantes que en el período anterior; el dolor romántico se con. vierte en una expresión de acento más intenso y angustiado; y, por razones hoy conocidas, la figura de Fuensanta, por lo menos como presencia concreta, tiende a desdibujarse en el volumen de 1919. Asimismo, como era de esperar, las visiones directas de la provincia ocupan menos espacio que antes. No es que desaparezca del todo la provincia sino que se espiritualiza, siendo portadora de los sentimientos del pocta. Es un añorar, un bien precioso no borrado nunca por completo, y a la provincia vuelve una y otra vez López Velarde hasta imaginarse el regreso final a su pueblo en "Humildemente", poema que es, no sin intención, el último del libro.

Hay, en Zozobra, no obstante, una importante poesía elegíaca que abre el volumen, en la cual López Velarde otra vez se despide de la mujer amada en tránsito a la muerte inevitable. Se trata, desde luego, de "Hoy como nunca", composición escrita por lo visto en unos mo. mentos de aguda crisis espiritual, ya que Josefa de los Ríos muere el 7 de mayo de 1917. En su desolación necesita de la paz que ella representa; $y$, en esta sentida evocación de la moribunda prodiga las imágenes religiosas y bíblicas, así como recuerdos concretos de la provincia y de su pasado. Quisiera insistir también en el hecho de que López Velarde dice que la esencia de Fuensanta es venerable, pero no deja de agregar inmediatamente que es quebradizo el vaso de su cuerpo. 
Ya ida la novia imposible de antaño, en varias composiciones de Zozobra usurpa su lugar la mujer de la capital (también presente en un poema del libro de 1916), tan enérgicamente retratada en el intenso poema "Día 13" y en la prosa "El don de febrero". La sentimentalidad de antes se tiñe ahora de franca sensualidad, y para ver con claridad su estado de alma es instructiva la repetida lectura de "En el solar" y "Fresnos y álamos", prosas recogidas en El minutero. López Velarde tiene clara conciencia del profundo cambio que se ha operado en su alma, y a esa transformación espiritual se refiere en varias ocasiones. Sin embargo, de modo indirecto Fuensanta está todavía presente en su recuerdo como un pretérito superado pero aún así perdurable. Escribe, por ejemplo, dirigiéndose a la mujer de la ciudad:

Los amados espectros de mi rito para siempre me dejan;

Y la pureza cede a la pasión:

Mis lirios van muriendo, y me dan pena;

pero tu mano pródiga acumula

sobre mí sus bondadas veraniegas,

("Transmútase mi alma...")

En otra composición significativa, también inspirada en la nueva musa capitalina, escribe López Velarde:

$¡$ ¡h tú, reveladora, que traes un sabor

cabal para mi vida, y la entusiasmas:

tu triunfo es sobre un motín de satiresas

y un coro plañidero de fantasmas!

("Que sea para bien...")

Como ya señalé hace varios años, en el poema recién citado y en otros, López Velarde parece entrever vagamente la posibilidad de conciliar en una sola presencia femenina los dos extremos amorosos. Ese anhelo anoroso de la mujer completa e integral llega a su cumbre en "Dejad que la alabe", poema que acentúa más una posibilidad que una realidad. Lo más sensual ("Próvida cual ciruela, / del profano compás / siempre ha de pedir más") repetidamente se conjuga con lo espiritual ("y lue 
go ... la paloma / que baja de las nubes"). Y con los siguientes versos remata ese nuevo ideal: "Que me sea total / y parcial, / periférica y central". Por fin este amor apasionado es como el anterior: un fracaso. A tal derrota alude López Velarde en ciertas poesías como "La lágrima" y "Despilfarras el tiempo". Así es que el poeta, entregado ahora en verdad a nuevas experiencias eróticas, no se olvida por completo de Fuensanta aunque su presencia se diluye y queda relegada a un pasado superado. Pronto, en un trasmundo, irá a su encuentro espectral.

Lo primero que se nota en una lectura de las poesías de $E l$ son del corazón es que vuelven a aparecer con renovada insistencia las estampas provincianas, y, relacionado con ellas, el recuerdo obsesionante de Fuen. santa, sin que se identifique por nombre como en el primer poemario. Tenemos sobre el particular el siguiente testimonio de Pedro de Alba, uno de los amigos más intimos de López Velarde:

...Quienes asistimos al alumbramiento de los poemas de El son del cordzónt, sabemos cómo se fue dibujando de nuevo el intimo retorno a Fuensanta; cómo su recuerdo y su figura se volvieron obsesión del poeta. Era el triunfo póstumo del primer amor y era también el llamado de una sombra misteriosa. Revivió las escenas familiares y trajo a primer plano los más lejanos episodios, se anegó en una ternura melancólica y agorera.

Sin embargo, desde un principio, se advierte que es una Fuensanta dis. tinta, ahora totalmente espiritualizada y menos concreta, que suele aparecer las más de las veces en una serie de imágenes cósmicas. Se ha con vertido en una realidad mucho más metafísica en comparación con la más bien sentimental de antes. No creo engañarme con una simetría cómoda al afirmar que en aquellos versos posteriores se dibuja un círculo perfecto: el libro, orgánicamente integrado con los otros, es en cierto sentido el retorno a los orígenes.

Esta breve colección de poesías es también algo más: en ella López Velarde toma otra vez sus temas esenciales, los reelabora y los contempla de una manera más reflexiva o resignada. Después de la pasión, la sere. nidad. Es evidente que está repensando toda su evolución sentimental y de ahí las frecuentes síntesis líricas de su trayectoria vital. Más que nada a mi juicio se trata de una contemplación meditada y menos vehemente de su propio desarrollo espiritual. Hasta en la forma misma, más regular ahora, su poesía última alcanza modalidades clásicas. Es el remanso después de la angustia de Zozobra. 
Aunque aquí me interesa sobre todo el reencuentro con la sombra de Fuensanta, quisiera recordar que $E l$ son del corazón es un libro lleno de voces, ecos y visiones de ultratumba. Se acentúa el presentimiento de la muerte y lo curioso es que la añoranza y la muerte suelen darse la mano, porque sólo es posible reconquistar el pasado a través de la muerte misma. Tienden a desaparecer las notas horroríficas aso. ciadas con la muerte en Zozobra a pesar de la frecuencia con que el poeta habla de buesos, de coldaveras y de esqueletos. En una sugestiva prosa anterior, publicada en 1916, López Velarde se pregunta qué hacer para curarse del horror a la tumba y de los imaginados tormentos de la fosa:

...Recurro a ti, a quien he amado. A ti mujer otoñal que llegas al descenso de la vida sin haber escuchado teorías inquietantes. Recurro con fe íntegra a ti, señora crepuscular, en cuya adoración se consumen en irresistible incendio romántico sesenta meses de mi juventud; a ti, cosecha que regocijaste a mozos labradores que hoy apenas son un recuerdo en tu mente de mujer derrotada por el tiempo; a ti, fruta de pasadas vendimias para mi boca adolescente; a ti, que en épocas en que nos conocimos tenías el corazón como playa en que los barcos deshechos auguraban lo irremediable de tu naufragio pasional; a ti, que en las amortiguadas pupilas tienes luz de cuarto menguante que hace clara las rutas de mi ensueño taimado. Cuando me enamoré de tu encanto (lo que sabes, no obstante la clausura perpetua de mis labios) no conocía aún al novísimo novelista para quien el amor es la gran melancolía del sexo... Libra, pues, mis rodillas, mi pecho, mi espalda y mi cabeza de una cruel y anticipada animación en el seno de la tierra. Sáname de este miedo pueril, que para logratlo tienes la gracia, en sus dos grandiosos sentidos: en el grave de la teología y en el risueño que es belleza de la mujer, fuerza de canto, armonía de la línea y virtud del verso. Hazme amar a la Madre Tierra.

Para medir el alcance que tiene la presencia de Fuensanta, entre metafísica y alucinante, son de especial importancia dos poemas, aunque en varios otros se perciben también directa e indirectamente sus innegables huellas. En el primero de ellos, "La ascensión y la asunción", López Velarde afirma que vive con él no sabe qué mujer perfecta e invisible. A toda hora ella lo eleva a las regiones celestiales y logra triunfar sobre el pasado erótico del poeta: 
Sobre caricaturas y parodias, enlazado mi cuerpo con el suyo, suben al cielo como dos custodias.

Su corazón de niebla y teología abrochado a mi rojo corazón, traslada, en una música estelar, el Sacramento de la Eucaristía.

Y finalmente el poeta da gracias a Dios por haber convertido la caída en vuelo, lo cual le permite trascender la miseria y las limitaciones de la vida mortal.

Aquel mismo motivo del vuelo, ahora más insistente y también fuera de este mundo, se acentúa en el hermético poema visionario titulado "El sueño de los guantes negros". En él Fuensanta se resucita, en una madrugada de invierno y de silencio, y, mientras suenan los ecos de una misa oceánica, el poeta va a su encuentro. En ese sueño suprarreal los amantes se unen por las cuatro manos, que a su vez son capaces de sostener el universo entero. La mujer ha surgido con los guantes negros y preguña López Velarde: "¿conservabas tu carne en cada hueso?" ¿Es espíritu o es carne Fuensanta? No hay contestación posible o por lo menos no la encuentra el poeta:

El enigma de amor se veló entero

en la prudencia de tus guantes negros.

$Y$ tras una estrofa incompleta en la cual se recuerda por lo visto la reali. dad de la muerte de la amada escribe López Velarde:

Pero en la madrugada de mi sueño, nuestras manos, en un circuito eterno la vida apocalíptica vivieron.

A Octavio Paz se deben algunas finas interpretaciones de ese poema, $y$ merecen citarse por lo menos en parte:

.. Ha cesado la separación pero la verdadera unión, como lo insinúa la prudencia de los guantes negros, es imposible. El poema, más que la consagración de un amor que se consuma parece ser el presentimiento de una eterna condenación... Sólo muerta, ya es- 
píritu puro, la amada puede ser realmente Fuensanta. La pregunta de "El sueño de los guantes negros" posee una resonancia equí. voca. ¿Fuensanta no acaba de ser espíritu porque el poeta sigue hechizado por el tiempo y sus trampas? ¿Cuál es el significado de esos guantes negros, cuya prudencia acentúa aún más su fúnebre erotismo? Son un obstáculo, una prohibición pero ¿qué prohiben: la unión de las almas o la de los cuerpos? Los amantes giran en un circuito eterno -imagen que recuerda un célebre pasaje de la Divina Comedita sin jamás fundirse, sin estar muertos ni vivos del todo, ¿en un paisaje que es del cielo o del infierno? $\mathrm{Y}$ ese amor ¿es amor a la vida o a la muette?

No creo que ni Paz ni yo hayamos sabido contestar a todas aquellas preguntas, erizadas de dudas enigmáticas, pero cabe recordar, no sólo la firme creencia de López Velarde en el dogma de la resurrección de la carne, sino que también, en repetidas ocasiones, afirma que el último adiós no supone "...la ruptura definitiva del hilo de oro que mantiene unidos los corazones" para los que creen "en el alma incorruptible y diáfana". En otra parte expresa su resignación ante la fuga de las excelencias de la carne, porque queda lo mejor: lo incorruptible y lo eterno. Hasta parece pensar en la posibilidad de que la amada pura resucite cuando escribe:

Reside en la carne virgen y preclara una salud rebosante que ordena las ruinas en el mismo orden en que fueron edificadas. ¡Resurred. ción!, claman los númenes de nuestra conciencia. ¡Resurrección!, claman los númenes de nuestros huesos. $Y$ en la demolición de las almas y de los cuerpos, la fausta alhucema ratifica un próspero mensaje de natividades.

Ahora que nos aproximamos al final de nuestro largo recorrido, conviene recordar que en nuestro viaje partimos de la despedida a Fuensanta para llegar al reencuentro con Ella en un trasmundo entrevisto en los sueños y visiones del poeta. López Velarde ha proclamado $l_{a}$ moral de la simetria; ha conocido el mundo por los cuatro costados (él diría en todos sus hemisferios); y, "revestido con la capa de polvo de la santa experiencia", parece buscar ahora cierto reposo o permanencia, aunque se da cuenta de la imposibilidad de reconciliar del todo los imperiosos dictados de su alma herida. Y, en tal estado de ánimo, ¿a dónde o a quién recurrir para intentar resolver la discordia? En aquella eterna 
imagen femenina busca la identidad de su propio ser y, a través de ella, muerta pero resucitada, le será posible "remontar el río de los años" y acudir "a la justicia original de todas estas cosas" que tanto bien le hicieron en el pasado. Más allá de los límites del mundo, pues, se re. nueva el diálogo reconfortante con Fuensanta, a veces una presencia luminosa y transfigurada. En ese reencuentro López Velarde revive su propio drama espiritual y, al revivirlo, procura explicarse a sí mismo. No importa que tal vez no descubra la respuesta final, pues, el verse eje de "El sueño de los guantes negros" es en realidad una pregunta, como ya advierte Paz. Lo que interesa es la búsqueda y de ahí la esencia pro. funda de la poesía de Ramón López Velarde.

AlleN W. Phillips

University of Texas

Mayo de 1971 